\title{
COLAGEM PALEOPROTEROZÓICA DE PLACAS ARQUEANAS DO CRÁTON DO SÃO FRANCISCO NA BAHIA
}

\author{
JOHILDO S. F. BARBOSA ${ }^{1} \&$ PIERRE SABATÉ ${ }^{2}$
}

\begin{abstract}
PALEOPROTEROZOIC COLAGE OF ARCHEAN PLATES OF THE SÃO FRANCISCO CRATON IN THE STATE OF BAHIA Recent petrological, geochronological and isotopic researches has identified four important Archean crustal segments in the São Francisco Cráton, SFC, in the state of Bahia. The oldest Gavião Block occurs in the WSW part of the SFC is composed essentially of granitic, granodioritic and migmatitic rocks. It includes remnants of TTG suites, considered to represent the oldest rocks in the South American continent $(\sim 3,4 \mathrm{Ga})$ and associated Archean greenstone belt sequences. The youngest segment, named the Itabuna-Salvador-Curaçá Belt is exposed along the Atlantic Coast, from the SE part of Bahia up to Salvador and then along a NE trend. It is mainly composed of tonalite/trondhjemites, but also includes stripes of intercalated metasediments and ocean-floor/back-arc gabbros and basalts. The Jequie Block, the third segment, is exposed in the SE-SSW area, being characterized by Archean granulitic migmatites with supracrustal inclusions and several charnockitic intrusions. The Serrinha Block (fourth segment) occurs to the NE, composed of orthogneisses and migmatites, which represent the basement of Paleoproterozoic greenstone belts sequences. During the Paleoproterozoic Orogeny, these four crustal segments collided, resulting in the formation of an important mountain belt. Geochronological constrains indicate that the regional metamorphism resulting from crustal thickening associated with the collision process took place c.a. 2.0 Ga.
\end{abstract}

Keywords: Geological, geochronological and isotopic research, Archean segments, Paleoproterozoic collision

\begin{abstract}
Resumo Pesquisas recentes petrológicas, geocronológicas e isotópicas permitiram identificar quatro importantes segmentos crustais Arqueanos no Cráton do São Francisco na Bahia. O mais antigo, Bloco Gavião, ocorre na parte WSW sendo composto essencialmente de rochas graníticas, granodioríticas e migmatíticas. Ele encerra não somente remanescentes de suites TTG, consideradas as mais antigas da América do Sul $(\sim 3,4 \mathrm{Ga})$, mas também greenstone belts com idades Arqueanas. O segmento mais jovem, denominado de Itabuna-Salvador-Curaçá é exposto ao longo da Costa Atlântica, começando na parte SE da Bahia, passando por Salvador e estendendo-se para NE. Ele é formado basicamente de tonalitos/trondhjemitos mas, inclui também faixas de rochas supracrustais associadas com gabros/basaltos de back-arc ou fundo oceânico. O terceiro, Bloco Jequié, ocorre na parte SE-SSW da área, sendo composto de migmatitos granulíticos, com inclusões de supracrustais que foram penetradas por diversas intrusões charnockíticas. O Bloco Serrinha, quarto segmento, ocorre na parte NE sendo composto de ortognaisses e migmatitos, os quais constituem o embasamento de sequiências greenstone belts Paleoproterozóicas. Durante a Orogênese Paleoproterozóica, estes quatro segmentos crustais colidiram resultando na formação de importante cadeia de montanhas. Estudos geocronológicos têm indicado que o metamorfismo regional resultante do espessamento crustal, gerado pelos processos colisionais ocorreu em torno de $2,0 \mathrm{Ga}$.
\end{abstract}

Palavras-chave: Pesquisas geológicas, geocronologicas e isotópicas, segmentos crustais Arqueanos, colisão Paleoproterozóica

INTRODUÇÃO O artigo é uma síntese dos dados mais recentes voltada para explicar a evolução geológica-geotectônica do Cráton do São Francisco na Bahia. Para a sua realização foram analisadas as mais importantes pesquisas petrológicas, geocronológicas e isotópicas dos últimos dez anos, relativas às suas rochas Arqueanas e Paleoproterozơicas. As subdivisões tectonoestratigráficas existentes foram reexaminadas nos seguintes segmentos: os antigos núcleos TTGs, o Bloco do Gavião, o Contendas-Mirante e seqüências semelhantes vizinhas, o Grupo Jacobina, o Complexo Jequié, o Cinturão Itabuna, o Núcleo Serrinha, o Bloco Mairi, além dos Greenstone Belts do Rio Itapicuru e do Capim, conforme consta do texto explicativo do novo mapa geológico do estado da Bahia (Barbosa \& Dominguez 1996). Estas unidades e as relações tectônicas antes referidas foram confrontadas com dados geológicos mais recentes obtidos por Santos Pinto (1996), Bastos Leal (1998), Sato (1998), Corrêa-Gomes (2000), Teixeira et al. (2000), Mello et al. (2000), Barbosa \& Peucat (2003, em preparação), Barbosa et al. (2003, em preparação) entre outros, visando melhor conhecimento da geologia.

Isto permitiu verificar que o embasamento ocupa cerca de 50\% da área total da Bahia, composto quase que exclusivamente por rochas metamórficas de alto a médio graus, enquanto as da fácies xisto verde dos greenstone belts ocupam pequenas áreas se comparadas com as de médio e alto graus.

Os novos dados permitiram agrupar as unidades listadas acima em quatro segmentos crustais, (Gavião, Jequié, Itabuna-SalvadorCuraçá e Serrinha), todos de idade arquena. Estes segmentos colidiram no Paleoproterozóico, um período com significativa produção de rochas metamórficas e granitóides associados.

Para o melhor entendimento desta evolução, nesta síntese as idades geocronológicas de formação das rochas e de metamorfismo estão listadas em ordem decrescente de valores aproximados. Com o mesmo objetivo, seções geológicas foram usadas para mostrar a posição final das rochas após colisão.

1 - Instituto de Geociências - Universidade Federal da Bahia. CPGG - Centro de Pesquisa em Geofísica e Geologia/UFBA. Rua Caetano Moura, 123 Federação, CEP 40210-340. Bahia, Brasil. E-Mail: johildo@cpgg.ufba.br

2 - IRD - Institut de Recherche pour le Developpement. SHIS, QI11, Conjunto 4, casa 19, CEP 71625 - 240, Brasília, D.F., Brasil. E-Mail: ird@apis.com.br 
AS PLACAS ARQUEANAS Cada segmento crustal mencionados está bem discriminado com relação às idades modelo $\mathrm{Sm}-\mathrm{Nd}$ (Fig. 1) e diferentemente posicionado no diagrama $\varepsilon_{\mathrm{Nd}} \times \varepsilon_{\mathrm{Sr}}$ (Fig. 2). Ambos diagramas indicam, do ponto de vista isotópico, que estes segmentos tiveram origem e evolução distintas. Dados geológicos referidos ao longo do texto corroboram esta distinção.

Bloco Gavião No Bloco Gavião (Figs. 1, 3) ocorrem dois grupos de TTGs, datados por U-Pb SHRIMP em zircões, ambos metamorfisados na fácies anfibolito, constituindo crosta continental, uma das mais precoces da Bahia. No primeiro grupo, com idades entre 3,4-3,2 Ga (TTG Sete Voltas/Boa Vista Mata Verde e Tonalito Bernarda, Tab. 1) modelagens geoquímicas (Martin et al. 1991) mostram que este se originou por fusão de basaltos toleiíticos e deixando anfibolitos ricos em granada ou eclogitos como resíduos. O segundo, com idades de 3,2-3,1 Ga. (Granitóides Serra do Eixo/Mariana/Piripá, Tab. 1) teve origem similar mas foi submetido a contaminação crustal (Martin et al. 1991, Marinho 1991, Santos Pinto 1996, Cunha et al. 1996, Bastos Leal 1998). Quanto às seqüências vulcano-sedimentares deste Bloco, estudos recentes mostram que a maioria foram greenstone belts denominados de Contendas Mirante, Umburanas, Guajerú e Mundo Novo (Marinho 1991, Mascarenhas \& Silva 1994, Cunha et al. 1996, Bastos Leal 1998). Estes greenstone belts, da fácies xisto-verde, se formaram em bacias intracratônicas, na crosta antiga TTG, com a produção inicial de rochas vulcânicas continentais com idades em torno de 3,3 Ga (Sub-Vulcânicas Ácidas do Contendas-Mirante e Basaltos toleiíticos da Formação Jurema Travessão, Tabela 1). Estes vulcanitos, após a separação das bordas das bacias intracratônicas e "oceanização", foram superpostos por komatiitos basais, basaltos toleiíticos com pillow-lavas, rochas piroclásticas e sedimentos químico-exalativos com idade da ordem de $3,2 \mathrm{Ga}$ (FFB-Formações Ferríferas Bandadas, Tab. 1). Em seguida as supracrustais foram soterradas por sedimentos detríticos com idades mínimas de 3,0-2,8 Ga (Sedimentos Detríticos dos Greenstone Belts de Umburanas e de Guajerú, Tabela 1).

A crosta granítica/granodiorítica/migmatítica, predominante no Bloco Gavião e equilibrada na fácies anfibolito exibe idades de 2,82,7 Ga (Ex: Granito Malhada de Pedra, Tabela 1) sendo interpretada como produto da fusão parcial da crosta continental antiga, TTG (Santos Pinto 1996) durante o fechamento das bacias intercratônicas antes referidas. Vulcânicas cálcio-alcalinas $(\sim 2,5 \mathrm{Ga})$, intrusões graníticas (Granito Pé de Serra, $\sim 2,5 \mathrm{Ga}$ ) e intrusões máficas-ultramáficas (Sill do Rio Jacaré, $\sim 2,4 \mathrm{Ga}$ ) ao lado de filitos e grauvacas estão associadas com os greenstone belts Arquenos deste Bloco (Marinho 1991).

Bloco Itabuna-Salvador-Curaçá O Bloco Itabuna-SalvadorCuraçá (Fig. 1,3) consiste de , no mínimo, quatro grupos de tonalitos/ trondhjemitos, três dos quais são arqueanos com idades próximas a 2,6 Ga e um é paleoproterozóico com idade em torno de $2,1 \mathrm{Ga}$ (Barbosa \& Peucat 2003, em preparação). São exemplos os Tonalitos de Ipiaú e Caraíba (Tabela 2), com idades obtidas em zircões pelos métodos $\mathrm{Pb}-\mathrm{Pb}$ evaporação e U-Pb SHRIMP (Ledru et al. 1993, Silva et al. 1997, Barbosa \& Peucat 2003, em preparação). Estes grupos são interpretados, principalmente com base em ETR, como resultado da fusão de crosta oceânica toleí́tica (Barbosa \& Peucat 2003, em preparação). O segmento Itabuna-Salvador-Curaçá também inclui corpos de charnockitos de $\sim 2,6 \mathrm{Ga}$ (ex: Charnockito Caraíba, Tabela 2) e faixas de rochas metassedimentares intercaladas (quartzitos com granada, gnaisses alumino-magnesianos com safirina, grafititos e formações manganesíferas) além de gabros/ basaltos de fundo oceânico e/ou bacias back-arc de fonte mantélica (Teixeira 1997). Todas estas rochas foram reequilibradas na fácies granulito, no Paleoproterozóico. Este segmento também contem importantes intrusões de monzonito com afinidade shoshonítica (Barbosa 1990) e idade em torno de 2,4 Ga (Monzonito Ipiaú, Tabela 2), segundo dados $\mathrm{Pb}-\mathrm{Pb}$ obtidos pelo método de evaporação em zircões (Ledru et al. 1993). Arcos de ilhas, bacias back-arc e zonas de subducção foram os ambientes predominantes durante a construção do Bloco Itabuna-Salvador-Curaçá (Figueirêdo 1989 , Barbosa 1990, 1997, Teixeira \& Figueirêdo 1991). Este foi fortemente afetado pela tectônica paleoproterozóica e, durante a construção do Orógeno Itabuna-Salvador-Curaçá, outros corpos de tonalito foram formados sintectonicamente.

Bloco Jequié Este bloco (Fig. 1,3), antes chamado de Complexo Jequié (Cordani 1973), durante o Arqueano foi caracterizado por (i) migmatitos heterogêneos com enclaves de supracrustais constituindo o componente mais antigo e de idades em torno de 3,0-2,9 Ga (Enclaves Básicos e Migmatitos Ubaira e Jequié, Tabela 3) (Wilson 1987, Marinho 1991, Marinho et al. 1994) e (ii) intrusões múltiplas, graníticas-granodioríticas mais jovens e de baixo e alto Ti (Fornari \& Barbosa 1994) e idade em torno de 2,8-2,7 Ga (Granitos/Granodioritos de Maracás, Laje e Mutuípe, Tabela 3) (Alibert \& Barbosa 1992). Estas intrusões eventualmente contêm megaenclaves dos migmatitos heterogêneos mais antigos. Tanto o componente mais antigo como o mais novo constituíram o embasamento de bacias intercratônicas tipo rifts (Barbosa et al. 2003, em preparação) onde basaltos e andesitos basálticos, cherts, formações ferríferas bandadas, grafititos e kinzigitos se acumularam (Barbosa 1990). As rochas do Bloco Jequié foram intensamente deformadas e re-equilibradas na fácies granulito, durante a colisão paleoproterozóica mostrada adiante.

Bloco Serrinha Este Bloco (Figs. 1, 3), exibe um importante episódio de formação de crosta conforme demonstram datações em ortognaisses graníticos-granodioríticos e tonalíticos que variam entre 3,1 e 2,8 Ga (Gaal et al. 1987, Oliveira et al. 1999, Mello et al. 2000, Rios 2002). Em um desses ortognaisses foi encontrado xenocristais de zircões datados a 3,6 Ga (Rios 2002), indicando que o plutonismo de 3,1-2,8 Ga (Ortognaisses Porfiríticos de Serrinha, Tonalito Rio Capim e Ortognaisses Araci, Ambrósio, Requeijão e Embasamento, Tabela 4) foi introduzido em crosta mais antiga (Rios 2002). Estas rochas plutônicas ácidas e intermediárias, equilibradas na fácies anfibolito possuem enclaves gabróicos e constituem o embasamento dos Greenstone Belts do Rio Itapicuru e Rio Capim, ambos do Paleoproterozóico.

A COLISÃO PALEOPROTEROZÓICA Evidências geológicas, principalmente dados estruturais, metamórficos e radiométricos sugerem a colisão destes quatros blocos Arqueanos (Fig. 4) durante o Paleoproterozóico, resultando na formação de importante cadeia de montanha denominada de Orógeno Itabuna-SalvadorCuraçá. Os traços desta colisão são mostrados não somente com os dados acima referidos, mas também com o estudo das rochas paleoproterozóicas, pré e sintectônicas, presentes nos segmentos crustais Arqueanos, principalmente aquelas dos Blocos $\mathrm{Ga}$ vião (Marinho 1991, Santos Pinto 1996, Bastos Leal 1998, Mougeot 1996), Itabuna-Salvador-Curaçá (Oliveira \& Lafon 1995, Ledru et al. 1997, Corrêa-Gomes 2000, Barbosa \& Peucat 2003, em preparação) e Serrinha (Silva 1987, Alves da Silva 1994, Oliveira et al. 


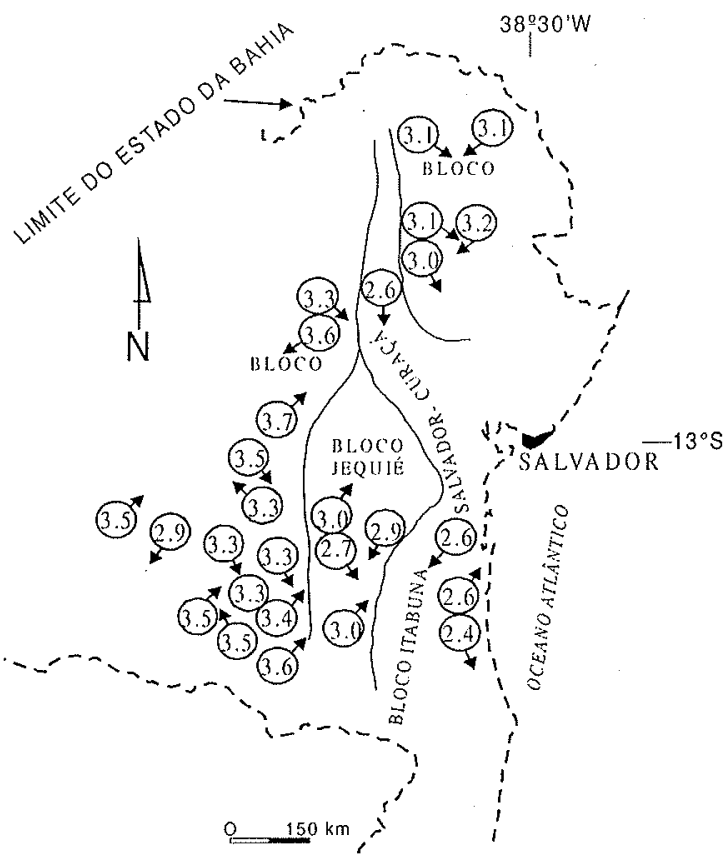

Figura 1 - Idades Arqueanas $S m / N d\left(T_{D M}\right)$ do Cráton do São Francisco na Bahia. (Fonte de dados ver tabelas 1 - 5).

Tabela 1-Bloco Gavião. Idades das principais rochas plutônicas e supracrustais arqueanas obtidas por diferentes métodos radiométricos. Martin et al. (1991) (1), Marinho (1991) (2) Nutman \& Cordani (1994) (3), Santos Pinto (1996) (4), Bastos Leal (1998) (5). Asteriscos = dados geocronológicos obtidos pelo método SHRIMP. RT = Rocha Total.

\begin{tabular}{|c|c|c|c|c|c|c|}
\hline \multicolumn{2}{|l|}{ Local } & \multirow{2}{*}{$\frac{\mathrm{Rb}-\mathrm{Sr}}{3420 \pm 90}$} & \multirow[t]{2}{*}{$\begin{array}{c}\text { Pb-Py } \\
\text { RT }\end{array}$} & \multirow{2}{*}{$\begin{array}{c}\begin{array}{c}\mathrm{Plp}-\mathrm{Pb} \\
\text { zircão }\end{array} \\
3394 \pm 5\end{array}$} & \multirow{2}{*}{\begin{tabular}{c|}
$\begin{array}{c}\text { U-Pb } \\
\text { zircr̃o }\end{array}$ \\
$3378 \pm 12 *$ \\
\end{tabular}} & \multirow{2}{*}{$\begin{array}{c}\mathbf{T}_{1 \mathrm{M} \mathbf{3}} \mathbf{N d} \\
3.6\end{array}$} \\
\hline Sete Voltas TTG ${ }^{1.2 .11}$ & $\mathrm{CM}$ & & & & & \\
\hline TTG Boa Vista/Matta Verde ${ }^{11,2,3,}$ & $\mathrm{CM}$ & $3550 \pm 67$ & $3381 \pm 83$ & & $3384 \pm 5 *$ & 3.5 \\
\hline Tonalito Bemirdata & $\mathrm{BE}$ & & & $3332 \pm 4$ & & 3.3 \\
\hline Granitóide Serza do Eixo ${ }^{(t)}$ & $\mathrm{SE}$ & & & $3158 \pm 5$ & & 3.3 \\
\hline Granitóide Maritunatit) & MA & & & $3259 \pm 5$ & & 3.5 \\
\hline Gintisses Piripatist & PI & & & & $32(x) \pm 11 *$ & 3.5 \\
\hline Granito Mallhada de Pedrai & $\overline{M P}$ & $2840 \pm 34$ & & & & 3.3 \\
\hline Gramilo Pé de Serrat & $\mathrm{PE}$ & $2560 \pm 110$ & & & & 3.1 \\
\hline $\begin{array}{l}\text { Sub-Vulcânicia Ácidà } \\
\text { Contendas }^{22}\end{array}$ & $\mathrm{CM}$ & & $3011 \pm 159$ & & $3304 \pm 31$ & 3.3 \\
\hline Toleítos Juremu-Travessĩo $0^{21}$ & $\mathrm{CM}$ & & $3010 \pm 160$ & & & 3.3 \\
\hline $\mathrm{FFB}^{(2)}$ & $\mathrm{CM}$ & & $3265 \pm 21$ & & & 3.3 \\
\hline Vulcênica Cílcio-Alcalina ${ }^{2 r}$ & $\mathrm{CM}$ & & $2519 \pm 16$ & & & 3.4 \\
\hline Sill Jacare ${ }^{(3)}$ & $\mathrm{CM}$ & & $2474 \pm 72$ & & & 3.3 \\
\hline Sedimentos Detriticos Unburamas ${ }^{(5)}$ & UM & & & & $\begin{array}{l}3335 \pm 24 * \\
3040 \pm 24 * \\
\end{array}$ & \\
\hline Sedimenthos Detríticos Guajenu ${ }^{\text {(s) }}$ & Gu & & & $\begin{array}{r}2861 \pm 3 \\
2664 \pm 12 \\
\end{array}$ & 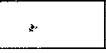 & \\
\hline
\end{tabular}

1999, Mello et al. 2000, Rios 2002) (Figs. 5, 6).

No Bloco Gavião (Figs. 5a, 6a) ocorrem (i) o Grupo Jacobina gerado em foreland basin (Ledru et al. 1997) e formado por xistos, formações ferríferas bandadas, formações manganesíferas, quartzitos, conglomerados e intrusões máfico-ultramáficas (Mascarenhas et al. 1992), onde metassedimentos siliciclásticos contêm zircões detríticos de idade mínima de 2,1Ga (Conglomerado Jacobina, Tabela 5) (Mougeot 1996) e (ii) a Formação Areião

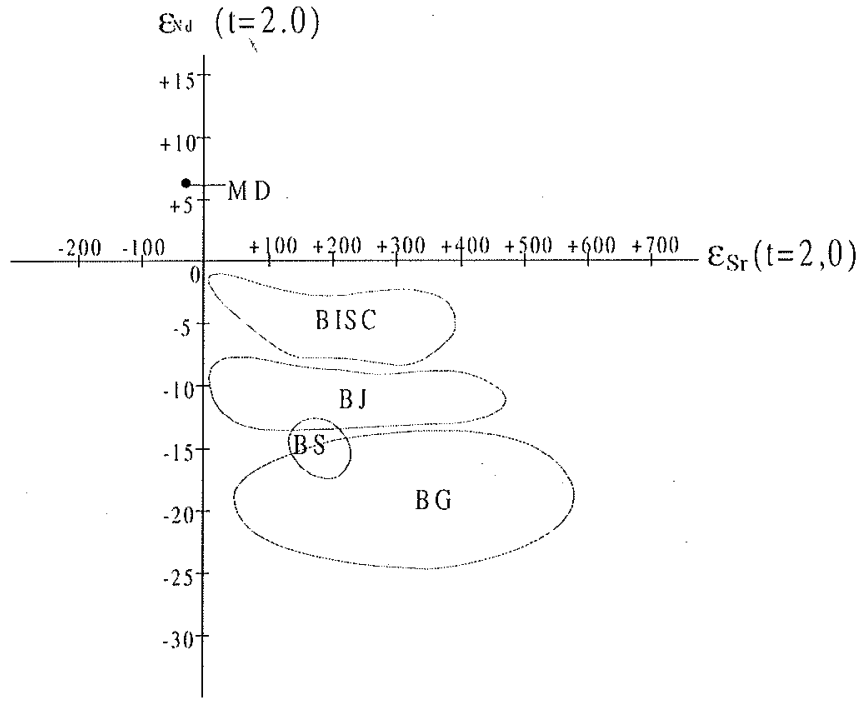

Figura 2 - Diagrama $\varepsilon_{N d} \times \varepsilon_{S r}(t=2.0 \mathrm{Ga})$ mostrando campos distintos de idade arqueana. As idades do BISC (Bloco ItabunaSalvador-Curaçá) são mais próximas ao MD (Manto Depletado). BJ (Bloco Jequié), BS (Bloco Serrinha) e BG (Bloco Gavião).

composta de arcóseos e arenitos que também contêm zircões detríticos de 2,1 Ga (Sedimentos Detríticos Contendas Mirante, Tabela 5) pelo método U-Pb SHRIMP (Nutman et al. 1994).

No Bloco Itabuna-Salvador-Curaçá (Figs. 5, 6), as mais importantes rochas paleoproterozóicas são (i) tonalitos e trondhjemitos com zircões datados em aproximadamente 2,1 Ga (Tonalito de Barra do Rocha, Itabuna e Pau Brasil e Quartzo-Monzonito de Mairi, Tab. 5) através dos métodos $\mathrm{Pb}-\mathrm{Pb}$ evaporação e $\mathrm{Pb}-\mathrm{Pb}$ rocha total (Ledru et al. 1993, Sabaté et al. 1994, Corrêa-Gomes 2000, Barbosa \& Peucat 2003, em preparação) e U-Pb SHRIMP (Silva $e t$ al. 1997); (ii) Noritos Caraíba e Gabros Medrado, ambos com idades ligeiramente mais antigas que 2,0 Ga (Oliveira \& Lafon 1995) (Tabela 5), contendo importantes depósitos de minérios, o primeiro de cobre e o segundo de cromo e, (iii) granitos sintectônicos datados em cerca de 2,1 Ga (Sabaté et al. 1990).

No Bloco Serrinha (Fig. 5) ocorrem os Greenstone Belts do Rio Itapicuru e do Capim formados em back-arc basin (Fig. 5a) (Winge 1984, Silva 1987, 1992, 1996) onde: (i) a unidade inferior de lavas metabasálticas ( 2,2Ga) (Vulcanicas Básicas Itapicuru, Tabela 5) consiste de metabasaltos toleííticos e tufos máficos, com formações ferríferas bandadas, cherts e filitos grafitosos; (ii) a unidade intermediária constituída de metavulcânicas félsicas $(\sim 2,1 \mathrm{Ga})$ (Vulcânicas Félsicas Itapicuru, Tabela 5), de composição variável de metandesito a metadacito cálcio-alcalinos; (iii) a unidade superior composta de espesso pacote de psefitos, psamitos e pelitos. Estes greenstone belts paleoproterozóicos diferem dos equivalentes arqueanos do Bloco do Gavião principalmente pela ausência de komatiitos nos primeiros.

A colisão paleoproterozóica ocorreu com movimento de quatro blocos no sentido NW-SE (Figs. 3, 4), identificado pela presença de falhas de empurrão e zonas transcorrentes tardias. As transcorrências tiveram uma cinemática em geral sinistral, como demonstram elementos de trama monoclínica vistos em seções paralelas às lineações de estiramento, normais ao acamamento composicional dos metamorfitos (Alves da Silva \& Barbosa 1997).

A convergência do Bloco Serrinha em direção ao Bloco Gavião 
Tabela 2 - Bloco Itabuna-Salvador-Curaçá. Idades das principais rochas plutônicas arqueanas obtidas por diferentes métodos radiométricos. Ledru et al. (1993) (6), Silva et al. (1997) (7). Asteriscos representam dados geocronológicos obtidos pelo método SHRIMP. RT= Rocha Total.

\begin{tabular}{|l|c|c|c|c|c|c|}
\hline \multicolumn{2}{|c|}{ Local } & Rb-Sr & $\begin{array}{c}\text { Pb-Pb } \\
\text { RT }\end{array}$ & $\begin{array}{c}\text { Pb-Pb } \\
\text { ziccão }\end{array}$ & $\begin{array}{c}\text { U-Pb } \\
\text { zircão }\end{array}$ & TDM Nd \\
\hline Tonalito Ipiaú $^{(6)}$ & IP & & & $2634 \pm 7$ & & \\
\hline Caraíba TTG $^{(7)}$ & CB & & & & $2695 \pm 12 *$ & 3.4 \\
\hline Charnoquito Caraíba $^{(7)}$ & CB & & & & $2634 \pm 19 *$ & 3.4 \\
\hline Monzonito Ipiaú $^{(6)}$ & IP & & & $2450 \pm 1$ & & 2.4 \\
\hline
\end{tabular}

Tabela 3-Bloco Jequié. Idades das principais rochas plutônicas arqueanas obtidas por diferentes métodos radiométricos. Marinho (1991) (2), Wilson (1987) (8), Marinho et al. (1994) (9), Alibert \& Barbosa (1992) (10). Asteriscos representam dados geocronológicos obtidos pelo método SHRIMP. RT = Rocha Total.

\begin{tabular}{|c|c|c|c|c|c|c|}
\hline \multicolumn{2}{|l|}{ Local } & $\mathbf{R b}-\mathbf{S r}$ & $\begin{array}{c}\mathrm{Pb} \cdot \mathrm{Pb} \\
\mathrm{RT}\end{array}$ & $\begin{array}{l}\mathrm{Pb}-\mathrm{Pb} \\
\text { zícão }\end{array}$ & $\begin{array}{c}\text { U-Pb } \\
\text { zircão }\end{array}$ & $\mathbf{T}_{\mathbf{M M}} \mathrm{Nd}$ \\
\hline $\begin{array}{c}\text { Enclaves Básicos } \\
\text { Ubaíra }^{\left.{ }^{8}, 9\right)}\end{array}$ & UB & & & & & 3.3 \\
\hline $\begin{array}{l}\text { Migmatitos } \\
\text { Ubaíma }{ }^{(8.9)}\end{array}$ & UB & $2900 \pm 24$ & & & & 3.2 \\
\hline $\begin{array}{l}\text { Migmatito } \\
\text { Jequié }^{(8,0)}\end{array}$ & IE & & & & & 2.9 \\
\hline $\begin{array}{c}\text { Granito } \\
\text { Maracús }{ }^{(2)}\end{array}$ & $\mathrm{MC}$ & $2800 \pm 12$ & $2660 \pm 70$ & & & 3.2 \\
\hline $\begin{array}{c}\text { Granodiorito } \\
\text { Laje }^{(10)}\end{array}$ & LJ & & & & $2689 \pm 1 *$ & 3.0 \\
\hline $\begin{array}{l}\text { Granodionito } \\
\text { Mutuípe }{ }^{(10)}\end{array}$ & MU & & & & $2810^{\text {s* }}$ & 3.0 \\
\hline
\end{tabular}

Tabela 4 - Bloco Serrinha. Idades das principais rochas plutônicas Arqueanas obtidas por diferentes métodos radiométricos. Gaal et al. (1987) (11), Oliveira et al.(1999) (12), Rios (2002)(19). RT = Rocha Total.

\begin{tabular}{|c|c|c|c|c|c|c|}
\hline \multicolumn{2}{|l|}{ Local } & $\mathbf{R b}-\mathrm{Sr}$ & $\begin{array}{c}\text { Pb-Pb } \\
\text { RT }\end{array}$ & $\begin{array}{l}\mathrm{Pb}-\mathrm{Pb} \\
\text { zircão }\end{array}$ & $\begin{array}{c}\text { U-Pb } \\
\text { zircão }\end{array}$ & $\mathbf{T}_{\mathrm{DM}} \mathrm{Nd}$ \\
\hline $\begin{array}{l}\begin{array}{l}\text { Ortognaisse Pofirítico } \\
\text { de Serrinha }{ }^{(11)}\end{array} \\
\end{array}$ & SR & & & & $\begin{array}{c}2991 \pm 22 \\
3070 \pm 3\end{array}$ & $\begin{array}{l}3.0 \\
3.2 \\
\end{array}$ \\
\hline Tonalito Rio Capim ${ }^{(12)}$ & $\mathrm{RC}$ & 3120 & & $\begin{array}{l}3000 \\
2900 \\
2650\end{array}$ & & \\
\hline Otognaisse Anci ${ }^{(19)}$ & $\mathrm{OA}$ & & & & 3055,15 & 3,12 \\
\hline Otognaisse Ambrosio ${ }^{(19)}$ & $\mathrm{OB}$ & & & & 3078,98 & 3,17 \\
\hline Ottognaisse Requeijão ${ }^{(19)}$ & OR & & & & 2807,04 & \\
\hline Ottognaisse Embasamento & $\mathrm{OE}$ & & & & 3095,94 & \\
\hline
\end{tabular}

(Fig. 5a) promoveu um importante encurtamento crustal (Fig. 5b), ao longo de um eixo, identificado pela vergência centrípeta dos granulitos situados ao norte do Orógeno Itabuna-Salvador-Curaçá. O orógeno continua no oeste do Gabão, África (Ledru et al. 1993).

Durante as etapas iniciais desta colisão, rampas frontais, com tectônica tangencial resultaram na sobreposição tectônica do Bloco Itabuna-Salvador-Curaçá no Bloco Jequié e ambos no Bloco Gavião (Fig. 6). Dobras recumbentes com vergência para oeste,

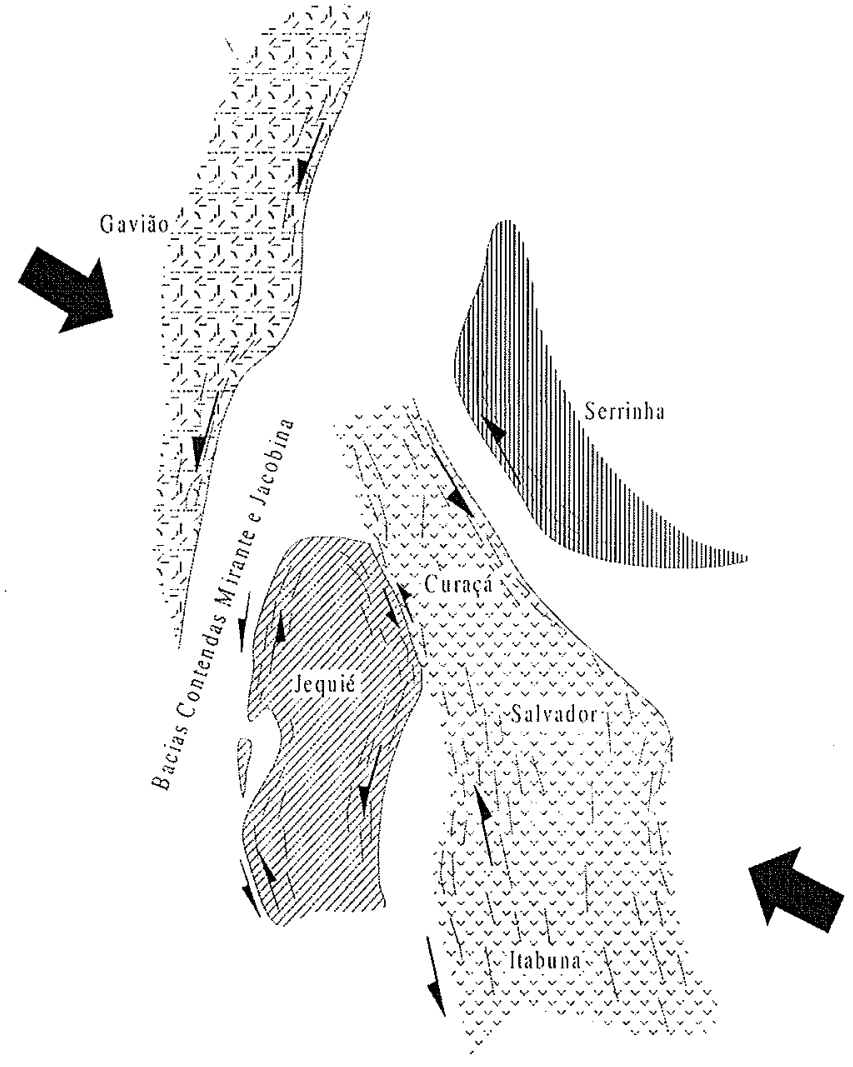

Figura 3 - Posições postuladas dos blocos arqueanos e início da colisão paleoproterozóica.

coaxialmente redobradas e exibindo formas isoclinais são encontradas algumas vezes nestes terrenos metamórficos de alto grau atestando a existência de reliquias estruturais da fase reversa (Alves da Silva \& Barbosa 1997).

O metamorfismo de alto grau Paleoproterozóico possue pressões médias de $7 \mathrm{Kbar}$ e temperaturas de cerca de $850^{\circ} \mathrm{C}$, com a idade de pico em aproximadamente 2,0 Ga (Barbosa 1990, 1997). Ele é considerado como proveniente da duplicação crustal resultado da superposição tectônica de blocos durante a colisão (Figs. $5 b, 6 b)$. Na parte central do Orógeno Itabuna-Salvador-Curaçá este metamorfismo alcançou a fácies granulito e, nas bordas, fácies anfibolito e xisto verde, conforme identificado nas zonas de transição entre a parte central do Orógeno e os Blocos Gavião e Serrinha (Fig. 5b, 6b). Durante a fase de levantamento, rampas tectônicas associadas a thrusts, modificaram a zonação metamórfica original em função da colocaçã்o de megablocos de rochas granulíticas sobre rochas das fácies anfibolito e xisto-verde (Fig. 5b) (Barbosa 1997). Esta configuração estrutural com terrenos de mais alto grau posicionados sobre outros de mais baixo grau é também observada no SSE e SSW do Cráton (Fig. 6b). Nestas áreas, a sobreposição tectônica ou cavalgamento do Itabuna-Salvador-Curaçá no Bloco Jequié transformou as rochas deste último, da fácies anfibolito para a fácies granulito. Em continuação, todo este conjunto de rochas de alto grau foi colocado sobre o Bloco Gavião (Fig. 6b).

Nos gnaisses de alto grau do Orógeno, reações de destruição das paragêneses granada-quartzo ou granada-cordierita e produção de simplectitos de ortopiroxênio-plagioclásio, têm sido interpretadas como indicação de alívio de pressão. Isto reforça a presença de colisão onde, grandes thrusts trouxeram blocos de ro- 


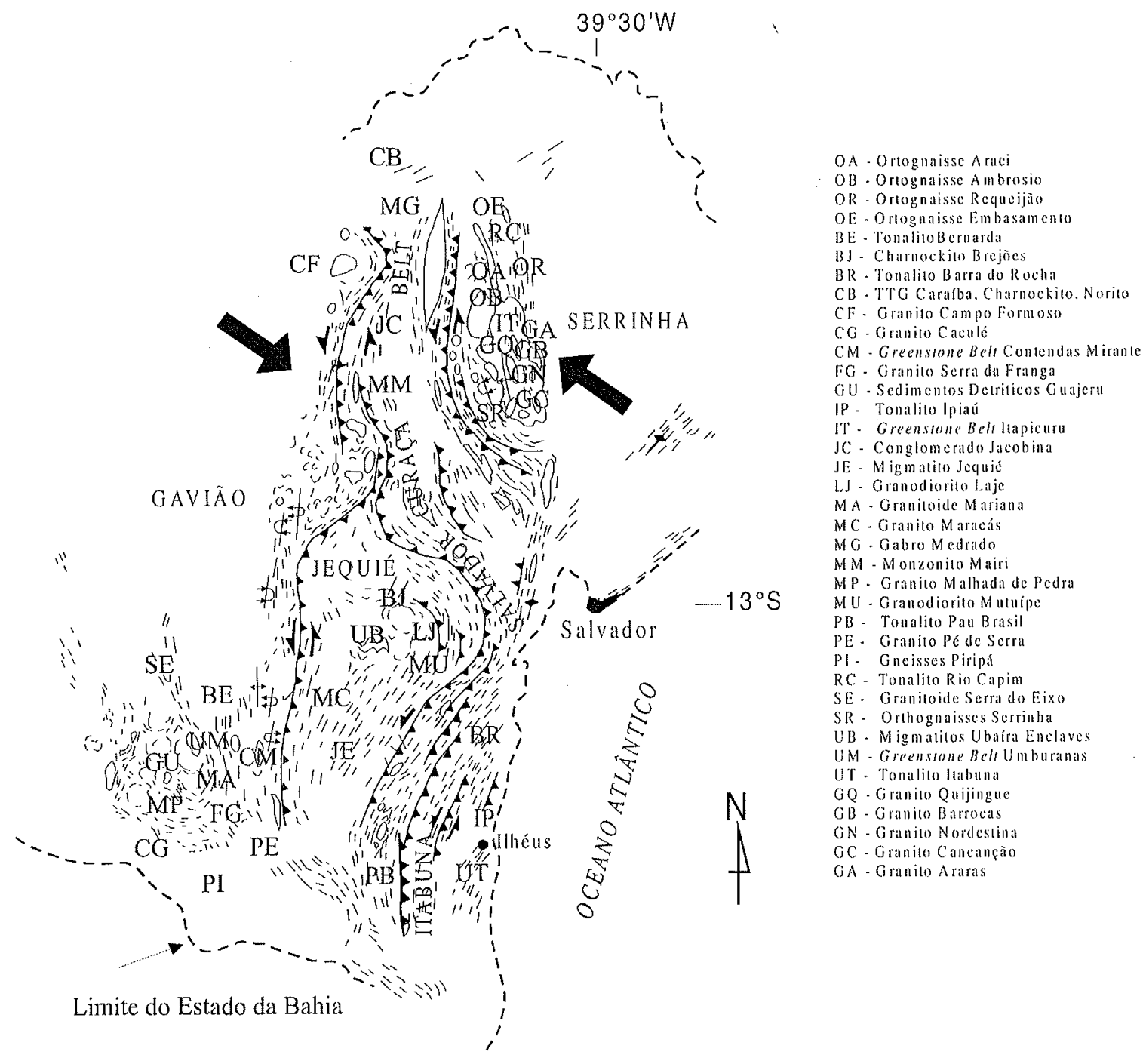

Figura 4 - Disposição dos blocos arqueanos após a colisão paleoproterozóica que formou o Orógeno Itabuna-Salvador-Curacá. Os dados estruturais de campo mostram uma cinemática global inicialmente reversa que evoluiu para sinistral. Também aparecem as localizações das amostras, clijas datações radiométricas estão listadas nas tabelas 1-5. Setas indicam o campo de tensão regional.

chas mais profundas para partes mais rasas da crosta. Diagramas PTt construídos a partir desses metamorfitos mostram a trajetórias do metamorfismo no sentido horário, confirmando o contexto colisional (Barbosa 1990, 1997, Leite 2002) (Figs. 5b, 6b).

Intrusões tardias de charnockitos e granitos penetraram esses segmentos crustais (Figs.5, 6). Corpos charnockíticos com idade de cerca 2,0 Ga (Barbosa et al. 2003, em preparação) (Charnockitos Brejões, Tabela 5) intrudiram a parte norte do Bloco Jequié e, corpos graníticos, em geral com características peraluminosas, algumas vezes ricos em biotita e, outras vezes, em muscovita, penetraram nos outros blocos. Estes últimos possuem uma composição próxima do mínimo ternário e mostram valores negativos de $\varepsilon_{N d}(t)$, $(-13$ a -5$)$. Suas características geoquímicas e isotópicas suportam a hipótese de que derivam predominantemente por fusão crustal (Sabaté et al. 1990). Com uma população maior no norte do Orógeno (Leite 2002), estes granitos exibem, em geral, idades $\mathrm{Pb} / \mathrm{Pb}$ e U/Pb de cerca 2,0 Ga (Granitos de Caculé, Serra da Franga, Campo For* moso, Poço Grande, Ambrósio, Quijingue, Barrocas, Nordestina, Cansanção, Araras, entre outros, Tabela 5) (Santos Pinto 1996, Bastos Leal 1998, Alves da Silva 1994, Mougeot et al. 1996, Rios
2002) e podem ser assumidos como tendo sido originados da fusão de rochas hidratadas da fácies anfibolito (Leite 2002), colocadas tectonicamente sob rochas da fácies granulito.

Deformações tardias formaram zonas de cisalhamento retrógradas nos blocos arqueanos. Admite-se que os corpos de sienitos (Itiuba, São Felix), com idades de 1.9 a 2.1 Ga (Conceição 1993, Rosa et al. 2001, Oliveira et al. 2002) se alojaram nessas zonas. Estes sienitos, tardi-orogenicos, intrudiram os granulitos depois de alcançarem ambiente crustal da fácies anfibolito (Figs. 5b, 6b).

CONCLUSÕES Apesar dos dados aqui apresentados permitirem explicar razoavelmente a evolução geotectônica dos terrenos metamórficos em consideração, grandes dificuldades ainda permanecem quando se tenta estabelecer os limites físicos e temporais entre o Arqueano e o Paleoproterozóico no Cráton do São Francisco na Bahia. Considerando os atuais conhecimentos permitem concluir que os eventos arqueanos e paleoproterozóicos ocorreram entre $-3,4 \mathrm{Ga}$ e $\sim, 9 \mathrm{Ga}$, deve se enfatizar que somente entre 2.4-2.3e $\sim 1.9$ Ga houve, com com mais certeza, a formação de rochas, tectonismo, metamorfismo, intrusão e erosão/exumação 
Tabela 5 - Idades das principais rochas plutônicas e supracrustais paleoproterozóicas obtidas por diferentes métodos radiométricos. Gaal et al. (1987) (11), Ledru et al. (1993) (6), Santos Pinto (1996) (4), Bastos Leal (1998) (5), Nutman et al. 1994 (13), Mougeot (1996) (14), Silva (1987) (15), Barbosa et al. 2003, em preparação (16), Oliveira \& Lafon (1995) (17), Corrêa-Gomes (2000) (18), Rios (2002)(19), Alves da Silva (1999)(20). Asteriscos = dados geocronológicos obtidos pelo método SHRIMP. RT = Rocha Total.

\begin{tabular}{|c|c|c|c|c|c|c|}
\hline \multicolumn{2}{|l|}{ Local } & $\mathrm{Rb}-\mathrm{Sr}$ & $\begin{array}{l}\mathrm{Pl} \cdot \mathrm{p} \cdot \mathrm{Pb} \\
\mathrm{RT}\end{array}$ & $\begin{array}{l}\mathrm{Pb}-\mathrm{Ph} \\
\text { zircão }\end{array}$ & $\begin{array}{l}\mathrm{U}-\mathrm{Pb} \\
\text { zircão }\end{array}$ & $\mathrm{T}_{\mathrm{BM}} \mathrm{Nd}$ \\
\hline Granito de Caculé ${ }^{(t)}$ & $\mathrm{CG}$ & & & $2015 \pm 27$ & & 2.6 \\
\hline Granito da Serra da Franga ${ }^{(+)}$ & $\mathrm{FG}$ & & & $2039 \pm 11$ & & \\
\hline Gratnito de Campo Formoso ${ }^{\text {its }}$ & $\mathrm{CF}$ & $1969 \pm 29$ & & & & 2.6 \\
\hline Sedimentos Detríticos Contendas Mirante ${ }^{(13)}$ & CM & & & & $2168 \pm 18 *$ & \\
\hline Conglomerado de Jacobinal ${ }^{(1+)}$ & JC & & & $\begin{array}{l}3,3,53 \pm 11 \\
2086 \pm 43\end{array}$ & & \\
\hline Vulcûnicus Búsicus lapicuru ${ }^{(15)}$ & IT & & $2209 \pm 60$ & & & 2.2 \\
\hline Vulcânicals Félsicils ltapicur!u ${ }^{(15)}$ & IT & $2080 \pm 90$ & $2109 \pm 80$ & & & 2.1 \\
\hline Granito de Poco Grande ${ }^{(5)}$ & TT & & & & $2070 \pm 47$ & \\
\hline Granito de Ambrósio (T) & IT & & & & 2000 & 2.1 \\
\hline Tonalito de Barra do Rochat ${ }^{(6)}$ & $\mathrm{BR}$ & & & $2092 \pm 13$ & & \\
\hline Tonalito de Itabuna ${ }^{(16)}$ & UT & & 2130 & & & 2.6 \\
\hline Tonallito de Pitu Brasil (183) & $\mathrm{PB}$ & & & $2089 \pm 4$ & & \\
\hline Norito de Caraíba ${ }^{(3)}$ & $\mathrm{CB}$ & & & & 2051 & 2.8 \\
\hline Quartzo-Monzonito de Mairi ${ }^{(17)}$ & MM & & & & $2126 \pm 19$ & \\
\hline Gabro de Medrado ${ }^{(17)}$ & MG & & & & 2059 & 2.9 \\
\hline Charnockitos Brcjôes & BJ & & & $2026 \pm 4$ & & \\
\hline Granito Quijingue $^{(1)}$ & GQ & & & & $2155 \pm 3$ & 3,27 \\
\hline Granito Barrocas ${ }^{(20)}$ & GB & & & $2127 \pm 5$ & & \\
\hline Granito Nordestina ${ }^{(i)}$ & $\mathrm{GN}$ & & & $2004 \pm 103$ & & \\
\hline Granito Conceição ${ }^{(1)}$ & $\mathrm{GC}$ & & & $2105 \pm 2$ & & 2,55 \\
\hline Ararisis $^{(19)}$ & GA & & & $2076 \pm 2$ & & 2,96 \\
\hline
\end{tabular}

(A)

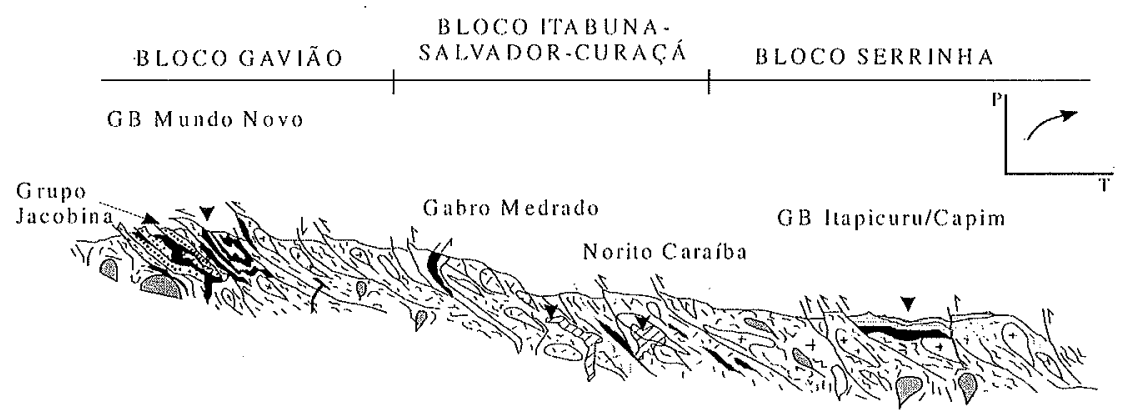

(B)

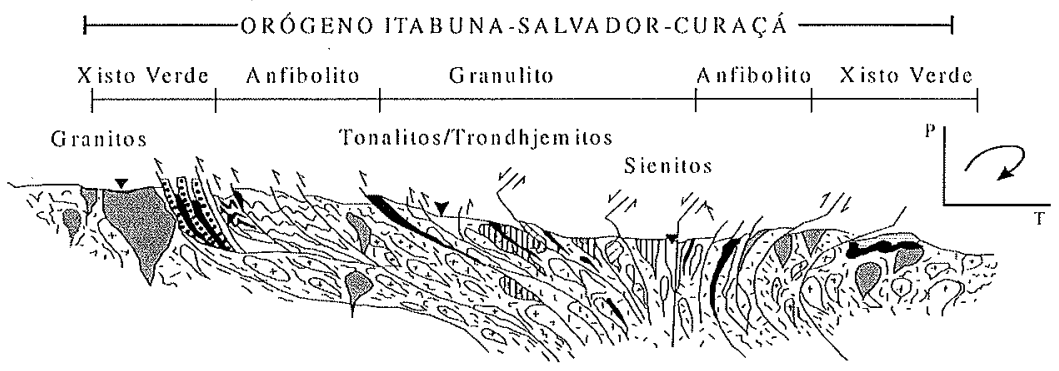

Figura 5-Perfis geotectônicos E-W no NNE do estado da Bahia, destacando apenas rochas de idade paleoproterozóica. (a) Estágio colisional intermediário no Paleoproterozóico com formação dos Greenstone Belts do Itapicuru e do Capim e acavalgamento do embasamento sobre o Grupo Jacobina. As intrusões máfico-ultramáficas de Caraíba e Medrado e de granitos sin-tectônicos estão relacionadas a este estágio. (b) Estágio final da orogênese com a colocação de sienitos e granitos. Atualmente nas porções oeste e leste podem ser observados terrenos granulíticos sobrepostos a terrenos anfibolíticos e xisto-verdes. Diagramas PTt localizados na lateral superior direita das seções. O sentido horârio da trajetória metamórfica atesta o contexto colisional. GB = Greenstone Belt.

que conduzem a um ciclo geotectônico. Este ciclo, que por comparação com outros locais do Brasil pode ser chamado de Transamazônico, teve seu pico em cerca de 2.1-2.0 Ga e sua intensidade praticamente apagou o registro de deformações e metamorfismos anteriores.
Agradecimentos Ao apoio do IRD - Institut de Recherche pour le Developpment, do CNPq e da CBPM-Companhia Baiana de Pesquisa Mineral para a realização deste artigo. Aos revisores da RBG pelas sugestões ao manuscrito. 


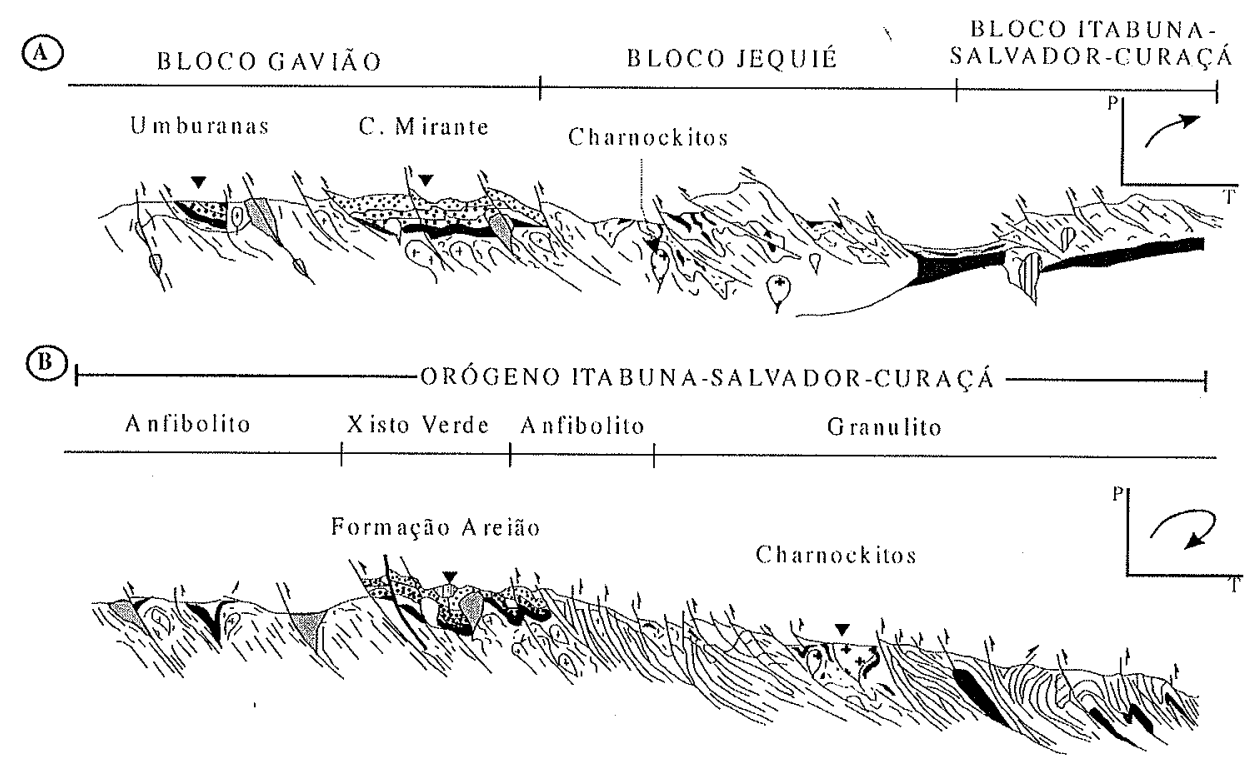

Figura 6 - Perfis geotectônicos EW no SSE-SSW do estado da Bahia, destacando apenas rochas paleoproterozóicas. (a) Estágio intermediário da colisão paleoproterozóica com deposição final de sedimentos siliciclásticos nos Greenstone Belts de Umburanas e Contendas Mirante, e início da produção de charnockitos na região de Brejões. (b) Estágio final da orogênese com cavalgamento do Bloco Itabuna-Salvador-Curaçá (granulitos) sobre o Bloco Jequié e deste sabre o Bloco Gavião (rochas das fácies anfibolito $e$ xisto-verde). Diagrmas PTt da lateral superior direita das seções obtidos a partir do estudo de gnaisses alumino-magnesianos.

\section{Referências}

Alibert C. \& Barbosa J.S.F. 1992. Âges U-Pb déterminés à la "SHRIMP" sur des zircons du Complex de Jequié, Craton du São Francisco, Bahia, Brésil. In: Réun. Sci. Terre, Toulouse, France, 14:4.

Alves da Silva F.C. 1994. Etude Structural do Greenstone Belt Paleoproterozoique du Rio Itapicuru (Bahia - Brésil). Université d'Orleans, França. Tese de Doutoramento. 307 p.

Alves da Silva F.C. \& Barbosa J.S.F. 1997. Evolução estrutural do cinturão granulitico do SE da Bahia: o exemplo da região de Ipiau. In: Simpósio Nacional de Estudos Tectônicos, 6, SBG - Núcleo Brasília, Pirenopolis, Goiás, Anais, 1: 241-243.

Barbosa J.S.F. 1990. The granulites of the Jequié Complex and Atlantic Mobile Belt, Southern Bahia, Brazil - An expression of Archean Paleoproterozoic Plate Convergence. In: D Vielzeuf, PH Vidal (eds.), Granulites and Crustal Evolution. Springer-Verlag, Clermont Ferrand, France, pp. 195-221

Barbosa J.S.F. 1997. Síntese do conhecimento sobre a evolução geotectônica das rochas metamórficas arqueanas e paleoproterozóicas do embasamento do Craton do São Francisco na Bahia. Rev. Bras. Geoc., 27:241-256.

Barbosa J.S.F, Dominguez J.M.L. 1996. Texto Explicativo para o Mapa Geológico da Bahia ao Milionésimo. SICM/SGM, Salvador, Bahia, Brasil, 400p.

Barbosa J.S.F. \& Peucat J.J. 2003. Idades $\mathrm{Pb} / \mathrm{Pb}$ dos grupos de tonalitos/ trondhjemitos do Bloco Itabuna-Salvador-Curaçá (em preparação)

Barbosa J.S.F, Martin H, Peucat J.J. 2003. Archean/Paleoproterozoic Crustal Domic Evolution of the Lage, Mutuipe, Brejões and Santa Ines Région. Jequié Block, Bahia, Brazil (em preparação).

Bastos Leal L.R. 1998. Geocronologia U/Pb (SHRIMP), ${ }^{207} \mathrm{~Pb} /{ }^{206} \mathrm{~Pb}, \mathrm{Rb}$ $\mathrm{Sr}, \mathrm{Sm} / \mathrm{Nd}$ e K/Ar dos Terrenos Granito-Greenstone do Bloco do Gavião: Implicações para a Evolução Arqueana e Paleoproterozóica do Craton do São Francisco, Brasil. Universidade de São Paulo, São Paulo, Tese de Doutoramento, 178p.

Conceição H. 1993. Sienitos do Estado da Bahia: Um Epítome do Tema e Interpretação à Luz do Conhecimento Atual. In: J.M.L Dominguez, A. Misi (eds.), O Cráton do São Francisco. SBG/SGM/CNPq, Spec Publi.:52-55.

Cordani U.G. 1973. Evolução geológica pré-cambriana da faixa costeira do Brasil, entre Salvador e Vitória. Universidade de São Paulo, São Paulo, Tese de Live Docência, 98p.

Corrêa-Gomes L.C. 2000. Evolução dinâmica da zona de cisalhamento neoproterozóica de Itabuna-Itaju do Colonia e do magmatismo fissural alcalino associado (SSE do Estado da Bahia, Brasil). Universidade Estadual de Campinas, São Paulo, Tese de Doutoramento, $236 \mathrm{p}$.

Cunha J.C, Bastos Leal L.R, Fróes R.J.B, Teixeira W.,Macambira M.J.B. 1996. Idade dos Greenstone Belts e dos Terrenos TTGs Associados do Cráton do São Francisco (Bahia, Brasil). In: SBG, Cong. Bras. Geol., 29., Salvador, Ancis, 1:62-65.

Figueirêdo M.C.H. 1989. Geochemical evolution of eastern Bahia, Brazil: A probably Early-Proterozoic subduction-related magmatic arc. $J$. South Amer. Earth Sci., 2:131-145.

Fornari A. \& Barbosa J.S.F. 1994. Litogeoquímica do Batolito EnderbíticoCranockítico do Complexo Jequié, na região de Laje e Mutuipe, Bahia. Rev. Bras. Geoc., 24:13-21.

Gaál G., Teixeira J.B.G., D’el Rey Silva L.J.H., Silva M. da G.D.A. 1987. Early Proterozoic crustal evolution and metallogenesis, Northwestern Bahia, Brazil. In: I ISGAM - Inter. Symp. Granites Assoc. Mineralizations, Salvador, (Palestra).

Ledru P., Cocherie A., Barbosa J.S.F., Johan V., Onstott T. 1993. Âge du métamorphisme granulitique dans le Craton du São Francisco (Brésil). implications sur la nature de l'Orogène Transmazonien. C. R. Acad Sci Paris, 211:120-125.

Ledru P, Milési J.P., Johan V., Sabaté P., Maluski H. 1997. Foreland basins and gold-bearing conglomerates: a new model for the Jacobina Basin (São Francisco Province, Brazil). Prec. Res., 86:155-176.

Leite C. de M.M. 2002. A Evolução Geodinâmica da Orogênese 
Paleoproterozóica nas regiões de Capim Grosso-Jacobina e Pintadas-Mundo Novo (Bahia-Brasil): Metamorfismo, Anatexia e Tectônica. Inst. de Geociências, Universidade Federal da Bahia, Bahia, Tese de Doutoramento, 411p.

Marinho M.M. 1991. La Séquence Volcano-Sedimentaire de ContendasMirante et la Bordure Occidentale du Bloc Jequié (Cráton du São Francisco-Brésil): Un exemple de Transition ArchéeanProtérozoique. Université Blaise Pascal, Clermont Ferrand, França, Tese de Doutoramento, 388p.

Marinho M.M., Vidal P.H., Alibert C., Barbosa J.S.F., Sabaté P. 1994 Geochronology of the Jequié-Itabuna granulitic belt and the Contendas Mirante volcano-sedimentary belt. In: M.C.H. Figueirêdo, A J Pedreira. (eds.), Petrological and Geocronologic evolution of the oldest segments of the São Francisco Craton, Brazil. Bol. IG-USP., 17:73-96.

Martin H., Sabaté P., Peucat J.J., Cunha J.C. 1991. Un segment de croute continentale d'age Archéean ancien ( 3.4 milliards d'années): le Massif de Sete Voltas (Bahia-Brésil). C R. Acad Sci Paris. 313 (Serie II) 531-538.

Mascarenhas J.F. \& Silva E.F.A. 1994. Greenstone Belt de Mundo Novo (Bahia): caracterização e implicações metalogenéticas no Cráton do São Francisco. CBPM, Salvador: Spec Publ., 32 p.

Mascarenhas J.F., Conceição Filho V.M.,Griffon J.C. 1992. Contribuição à geologia do Grupo Jacobina na região Jacobina/Pindobaçu. $I n$ SBG, Cong. Bras. Geol., 37, São Paulo, Res. Expand., 2:141-142.

Mello E.F., Xavier R.P., Mcnaughton N.J., Fletcher I., Hagemann S., Lacerda C.M.M., Oliveira E.P. 2000. Age constraints of felsic intrusions, metamorphism, deformation and gold mineralization in the paleoproterozoic Rio Itapicuru greenstone belt, NE Bahia State, Brazil. In: International Geological Congress, 31., Abstract Volume, Special Symposium 18.4 - Stable and radiogenic isotopes in metallogenesis. CD-ROM.

Mougeot R. 1996. Etude de la limite Archéen-Proterozoic et des mineralisations de Au, U associés: Exemples de la Region de Jacobina (Etat de Bahia, Brésil) et de Carajás (Etat de Pará, Brésil). Univ. Montpellier, França, Tese de Doutoramento, 301 p.

Mougeot R., Respaut J.P., Marcoux E., Milési J.P., Ledru P., Johan V. 1996. Geochemical and mineralogical characterizations of sulphide associated to the Jacobina gold mineralizations (Bahia-Brazil). In: SBG, Cong. Bras. Geol., 39. Salvador, Res. Expandidos, 3:318-320.

Nutman A.P. \& Cordani U.C. 1994. SHRIMP U-Pb zircon geochronology of archean gneisses and Contendas-Mirante Conglomerates, São Francisco Craton. In: M.C.H. Figueirêdo \& A.J. Pedreira (eds.), Petrological and geocronologic evolution of the oldest segments of the São Francisco Craton, Brazil. Bol. IG-USP. 17:99-115.

Nutman A.P., Cordani U.G., Sabaté P. 1994. SHRIMP U-Pb ages of detrital zircons from the Early Proterozoic Contendas-Mirante supracrustal belt, São Francisco Craton, Bahia, Brazil. J. South Amer. Earth Sci. 7: 109-114.

Oliveira E.P. \& Lafon J.M.. 1995. Age of ore-rich Caraíba and Medrado. Bahia, Brazil. In: SBGq, Cong. Bras. Geoquim., 5, CD-ROM.

Oliveira E.P., Lafon J.M., Souza Z.S. 1999. Archean-Proterozoic transition in the Uauá Block, NE São Francisco Craton, Brazil: U-Pb, $\mathrm{Pb}-\mathrm{Pb}$ and Nd isotopé constraints. In: SBG, SNET, 7, Lençóis, Bahia, Anais, 1:38-40.

Oliveira E.P., Mello E.F., McNaughton N., Choudhuri A. 2002. SHRIMP $\mathrm{U}-\mathrm{Pb}$ age of the basement to the Rio Itapicuru Greenstone Belt, NE São Francisco Craton. In: SBG, Congr. Bras. Geol., 41, João Pessoa, Anais, 522.

Rios D.C. 2002. Granitogenese no Núcleo Serrinha, Bahia, Brasil: Geocronologia e Litogeoquimica. Inst. de Geociências, Universidade Federal da Bahia, Bahia, Tese de Doutoramento, 233p.

Rosa M.L.S., Conceição H., Macambira M.J.B., Scheller T., Martin H.,
Bastos Leal L.R. 2001. Idade Pb-Pb e assinatura isotópica Rb-Sr e Sm-Nd do magmatismo sienítico Paleoproterozóico no sul do Cinturão Móvel Salvador-Curaçá: Maciço Sienítico de São Félix, Bahia. Rev. Bras. Geoc., 31 (1), 397-400.

Sato K. 1998. Evolução Crustal da Plataforma Sul Americana com base na geoquínica isotópica Sm-Nd. Universidade de São Paulo, São Paulo, Tese de Doutoramento, 297p.

Sabaté P., Marinho M.M., Vidal P., Vachette M.C.. 1990. The 2-Ga peraluminous magmatism of the Jacobina-Contendas Mirante belts (Bahia-Brazil): geologic and isotopic constraints on the sources. Chem. Geol., 83:325-338.

Sabaté P., Peucat J.J., Melo R.C., Pereira L.H.M. 1994. Datação por Pb evaporação de monozircão em ortognaisse do Complexo Caraíba. Expressão do Acrescimento Crustal Transamazônico do Cinturão Salvador-Curaçá (Craton do São Francisco-Bahia, Brasil). In: SBG, Congr: Bras. Geol., 38. Belo Horizonte, Resumos Expandidos, 1:219220.

Santos Pinto, M. A. 1996. Le Recyclage de la Crôte Continentale Archéene: Exemple du Bloc du Gavião - Bahia, Brésil. Université de Rennes I, França, Tese de Doutoramento, 193p.

Silva M.G. da. 1987. Geochemie, petrologie und geotektonische etwicklung eins Proterozoischen greunsteignertels, Rio Itapicuru, Bahia, Brazilien. Universidade de Freiburg, Alemanha, Tese de Doutoramento, $125 \mathrm{p}$.

Silva M.G. da. 1992. Evidências Isotópicas e Geocronológicas de um Fenômeno de Acrescimento Crustal Transamazônico no Cráton do São Francisco, Estado da Bahia. In: SBG, Cong. Bras. Geol., 37, São Paulo, Anais, 2:181-182.

Silva M.G. da. 1996. Sequências metassedimentares, vulcanossedimentares e Greenstone Belts do Arqueano e Proterozóico Inferior. In: J.S.F. Barbosa \& J.M.L. Dominguez (eds.), Geologia da Bahia: Texto Explicativo para o Mapa Geológico ao Milionésimo, SICM/SGM Salvador. Spec Publ., 85-102

Silva L.C. da, McNaughton N.J., Melo R.C., Fletcher I.R. 1997. U-Pb SHRIMP ages in the Itabuna-Caraíba TTG hight-grade Complex: the first window beyond the Paleoproterozoic overprint of the eastern Jequié Craton, NE Brazil. I $n$ : SBG, I Intern. Symp. Granites and Associated Mineralisations, Salvador, Abstracts, 1: 282-283.

Teixeira L.R. 1997. O Complexo Caraíba e a Suite São José do Jacuipe no Cinturão Salvador-Curaçá (Bahia-Brasil): Petrologia, Geoquímica e Potencial Metalogenético. Universidade Federal da Bahia, Bahia, Tese de Doutoramento, 201p.

Teixeira W., Figueiredo M.C.H. 1991. An outline of Early Proterozoic crustal evolution in the São Francisco Craton, Brazil: a review. Prec. Res., 53(1/2):1-22.

Teixeira W., Sabaté P., Barbosa J.S.F., Noce C.M., Carneiro M.A. 2000. Archean and Paleoproterozoic Tectonic evolution of the São Francisco Craton, Brazil, In: U.G .Cordani, E.J. Milani, A. Thomas Fitho, D.A. Campos. (eds.), Tectonic Evolution of the South America. In: Int. Geol. Congr. 31, Rio de Janeiro, Brazil, 101-137.

Winge M. 1984. A Sequência Vulcanossedimentar do Grupo Rio Capim, Bahia. In: P.V.S. Viveiros \& F.B. Duarte (eds.), Geologia e Recursos Minerais do Estado da Bahia, Textos Básicos, SME/CPM, Salvador, Spec. Publ., 5: 43-103.

Wilson N. 1987. Combined Sm-Nd, Pb/Pb and RbSr geochronology and isotope geochemistry in polymetamorphic precambrian terrains: examples from Brazil and Channel Island, U.K..Oxford University. U.K., Dissertação de Mestrado, s/p.

Manuscrito TM-002

Recebido em 30 de outubro de 2002

Revisão dos autores em 12 de dezembro de 2002 Revisão aceita em 15 de dezembro de 2002 